\title{
Habermas y Levinas: hacia el diálogo desde dos niveles
}

Victoria Tenreiro Rodríguez

Universitat de Valencia, España

victoriatenreiro@gmail.com

El diálogo es una de las formas de expresión ineludibles de la convivencia y la democracia actual. Su presencia en la vida pública hace posible el paso desde una concepción agregativa hacia una concepción deliberativa de la democracia ${ }^{1}$, como un modo de ir más allá de la apariencia de un determinado gobierno, hacia la democratización permanente de las estructuras que lo sostienen.

A través del diálogo, llevado a cabo ante la presencia del otro y mediante el proceso de dar y pedir razones que lo caracteriza, nuestra voluntad se forma y transforma conjuntamente con la voluntad de los demás; después de escuchar a los otros, nadie sale igual a como entró. Se abren, de esta manera, espacios para la formación colectiva de la voluntad y, en consecuencia, para el reconocimiento del bien común.

De esta manera, se amplía el alcance de los principios democráticos hacia las bases de la sociedad. Si bien no conocemos la democracia perfecta, consideramos que el diálogo puede mejorar las condiciones democráticas de muchos de

1 Diferencia expuesta por Cortina (2004: 143-161). 
los países del mundo; sin embargo, los contextos no son los mismos. Mientras que en algunos países donde la democracia está enraizada ${ }^{2}$ la tarea consiste principalmente en mejorar las condiciones de realización del diálogo o elevar su calidad, en otros países de regímenes híbridos o, peor aún, abiertamente autocráticos, se trata de hacer posible el inicio de los procesos de diálogo que, a su vez, generen la democratización siempre necesaria de las estructuras sociales.

No todas las teorías sobre el diálogo, la deliberación o la democracia se ajustan necesariamente a todos los contextos sociopolíticos. En este último sentido, nuestro estudio se apoya en la idea de que es necesario cuestionar los alcances de algunas de las más relevantes dentro de los contextos de países en proceso de consolidación democrática.

Por lo tanto, las preguntas que motivan mi trabajo no radican ya en qué hacer para mejorar la democracia o los procesos de diálogo en general, sino que intentan indagar en los supuestos que subyacen a la deliberación ${ }^{3}$, teniendo como punto de partida contextos que se le hacen esquivos ${ }^{4}$ : ¿qué es lo que nos impide dialogar?, ¿qué es lo que nos impide mirar o escuchar al otro?; o desde su formulación positiva: ¿dónde está la fuente que nos empuja a mirar, escuchar y dialogar con el otro?

Hacer explícitos los supuestos o condiciones que hacen posible el inicio del diálogo nos ayudará a profundizar en al-

2 Término traducido de Wolfgang Merkel. Para ampliar el concepto: Merkel, 2004: 33-58.

3 En el presente artículo uso los términos «diálogo» y «deliberación» en el mismo sentido, destacando con ello los procesos dialógicos implícitos en toda deliberación.

4 Si bien por razones de tiempo y espacio no desarrollaré las interpretaciones que me han servido de referencia en este sentido, dejo el nombre de sus autores y obras principales: Moreno, 2008 y González Fabré, 2008. 
gunas de sus fuentes y a comprender cuáles podrían ser los factores que orienten o empujen nuestra conducta en ese sentido. Creemos que se trata de cuestionamientos que nos llevan al ámbito de la motivación moral, es decir, al campo donde se reúnen las controvertidas preguntas por las fuentes de la moralidad y la conducta moral.

De esta manera, surge la posibilidad de replantearse el origen de los procesos de diálogo social, procurando mayor pertinencia en el establecimiento de soluciones al problema de la falta o ausencia de diálogo.

En primer lugar, presentaré algunas de las condiciones que hacen posible la deliberación dentro de la teoría habermasiana de la ética discursiva, como un modo de profundizar en las fuentes del diálogo dentro de esta propuesta.

En segundo lugar, presentaré algunas ideas de Emmanuel Levinas, en mi afán de profundizar en un proceso crítico que permita replantear el problema de las fuentes del diálogo como parte de los procesos de motivación moral, reposicionando las ideas de Jürgen Habermas en este campo.

Finalmente, se exponen nuestras conclusiones sobre lo que planteamos como dos niveles de motivación moral para el diálogo, útiles sobre todo en sociedades que se encuentran en proceso de consolidación democrática 5 .

$5 \quad$ Cabe aclarar que estas ideas han sido desarrolladas de modo exhaustivo en el siguiente trabajo: Tenreiro, V. (2013). Motivación moral para el diálogo: Aportes desde Jürgen Habermas y Emmanuel Levinas, presentado en diciembre 2013, a fin de optar al título del Máster en Ética y Democracia de la Universitat de Valencia. 
Jürgen Habermas: las fuentes del diálogo desde la perspectiva de la ética discursiva

El planteamiento habermasiano de la ética del discurso constituye una referencia importante en la configuración de políticas de acción y formación orientadas al diálogo: la concepción de una razón comunicativa -constituida dialógicamente-, la toma de perspectiva mutua, etcétera, constituyen fundamentos para el planteamiento de dinámicas sociales abiertas al reconocimiento del otro, a las prácticas de diálogo argumentativo, a los procesos de dar y pedir razones, etcétera; sin embargo, cuando intentamos leer la ética discursiva motivados por la necesidad de comprensión y aplicación a contextos sociopolíticos que no están consolidados democráticamente nos encontramos con algunas dificultades.

Se trata de sociedades cuyos rasgos no sólo han contribuido al quiebre de las pretensiones de validez de los actos comunicativos, sino también niegan la posibilidad de segundas oportunidades (ver García Marzá, 1992: 50). Dicho en otras palabras, la dinámica social no permite el paso al nivel discursivo en la búsqueda de resolución de los conflictos sociales. Los actos comunicativos no funcionan, y el diálogo tiende simplemente a cerrarse. ¿Significa esto la absoluta inadecuación de la ética discursiva a contextos como el descrito? ¿Simplemente cerramos los textos deliberativos y nos remitimos a teorías sobre la guerra? ¿Qué aportes podríamos esperar de la teoría habermasiana en la motivación al diálogo?

Parto de la hipótesis de que hay varios supuestos o condiciones que hacen posible el diálogo dentro de la ética discursiva y que muchas veces pasamos por alto. Tales condiciones, como veremos a continuación, no se dan en algunas sociedades, aunque puedan resultar obvias para otros contextos. 
Es esta tarea de darles identidad y hacerlas evidentes, por lo menos a algunas de ellas, la que nos ocupa en este momento. Quizás allí podría radicar el porqué de la inadecuación o la poca significatividad de la teoría habermasiana para algunos contextos.

El lenguaje como expresión y construcción de mundo: el poder creador del lenguaje

Estoy convencido de que la deliberación no puede sólo presuponer condiciones democráticas para su realización, sino que debe contribuir a generarlas. De allí el empeño en una posible relectura de la propuesta habermasiana, poniendo el acento en el poder creador del lenguaje.

Si asumimos que el lenguaje es sólo un producto de un mundo de vida que en último caso está cerrado a otros mundos, podemos decir entonces que habrá siempre un alcance pobre en los propósitos de diálogo entre personas, pueblos o culturas diferentes; pero si entendemos al lenguaje también como hacedor de mundos y logramos abrir nuestro lenguaje al Otro, creando efectivamente un contexto discursivo común, quizás eso vuelva a llegar a cada mundo de vida y lo reconfigure sobre la base de prácticas comunes. Así, el lenguaje es acción social en dos sentidos: en cuanto expresa, y también en cuanto construye mundos. En el diálogo, el lenguaje puede ser concebido como posibilidad de construir un topos común, lugares/mundos comunes y, en este sentido, abre caminos que hasta ese momento podían plantearse inexistentes. A eso me refiero cuando hablo del poder creador del lenguaje. 
Condiciones que hacen posible el diálogo en la ética discursiva

Apoyándome en la idea de que es en la ética discursiva donde Habermas sitúa la mayoría de las bases o condiciones donde radican la posibilidad del diálogo y la deliberación, he escogido algunas de sus obras representativas sobre el tema. Desde allí, y valiéndome de herramientas de análisis del discurso argumentativo, he llegado a una serie de conclusiones sobre la presencia de las condiciones o supuestos que hacen posible el diálogo. Las expongo a continuación:

1) La referencia a un vínculo en el que ya se está con el otro, antes de su reconocimiento como interlocutor válido. Escucho al otro y le hablo, si admito su presencia y el vínculo conmigo. Cuando no se le reconoce simplemente como Otro y no se tiene experiencia del vínculo, no hay reconocimiento del otro como interlocutor que sea posible.

Es, para Habermas, un problema que no pertenecería a la ética cognitivista que defiende (ver Habermas, 2000: 193) ${ }^{6}$, en cuanto nos remite a sentimientos, elementos no racionales, imaginativos, emocionales o, peor aún, entra dentro del espacio de la fundamentación existencial que, según el autor, nos lleva a la metafísica y restringe la pluralidad dentro de una visión comprensiva del ser humano (ver Habermas, 2000; 183-205). De esta manera, el autor descarta su tratamiento y desarrollo dentro de la teoría de la ética del discurso, por lo

6 Crítica que desarrolla cuando hace referencia a la «pregunta existencial» de Karl Otto Apel: ¿Por qué ser moral? 
menos en principio; sin embargo, insisto, esto no nos puede llevar a desconocer su importancia como condición para que el diálogo y la deliberación sean posibles.

2) La racionalización del mundo de la vida, esto es, un apalabramiento que dé sentido a los modos de vivir. Se pone en relevancia la necesidad de hacer lenguaje e identificar lo que se vive, convirtiendo las vivencias en experiencias dotadas de sentido y, más que expresarlas, poder comunicarlas. Para Habermas, este apalabramiento implica la capacidad para articular opiniones frente al mundo y dar razones de estas opiniones, favoreciendo la toma de postura. Si no hay apalabramiento, si no hay racionalización, no hay sentido; destacaría: no hay sentido compartido.

Esta racionalización va muy vinculada también a la presuposición de:

3) Una elevada conciencia sobre el proceso comunicativo: En uno de sus textos (Habermas, 2008: 71), el autor enfatiza cómo la conciencia sobre los procesos comunicativos de los que formamos parte son una forma de generar ese topos o lugar y, por qué no, «sentir» común que propicia el diálogo. Ante la problemática de cómo hacer que proceda un diálogo frente a concepciones de mundo distintas, una de las respuestas posibles consistiría en procurar la conciencia sobre los presupuestos comunicativos del entendimiento mediado lingüísticamente (presupuestos pragmáticos), y dejando que sea dentro de ese territorio y no en la dimensión sustantiva 
de los contenidos donde se identifiquen primeramente las orientaciones comunes. De esta manera se evita el desconcierto que, en un primer momento, puede derivar de la pluralidad y se podría suponer que se suman más fácilmente los distintos actores a la idea de deliberar, mientras la discusión sobre los contenidos va surgiendo ulteriormente. Discutiendo lo uno se abona en el terreno de lo otro y, al mismo tiempo, se van generando campos argumentales comunes.

4) Se presupone la institucionalización de las sociedades (se presupone sociedad, podría incluso decirse) $\mathrm{y}$, con ello, se le da un peso enorme a las garantías jurídicas de la trama social. Si no hay instituciones, o siendo más complacientes, si no hay un nivel institucional consolidado -esto es, aunque los procesos institucionales puedan ser mejorables-, no hay canales de diálogo. En la democracia deliberativa habermasiana las instituciones juegan un rol clave, incluso en el proceso de formación de la opinión pública.

En conjunción con la condición de racionalización o apalabramiento a la que hacíamos referencia anteriormente, la institucionalización tiene que ver, a su vez, con los procesos de explicitación de las formas de organización efectivamente funcionantes, muy relevantes en sociedades no consolidadas democráticamente. De un modo más preciso, si se promueve la necesidad de explicar e identificar las formas de la organización social que se dan en los diversos contextos, independientemente de que éstas sean coherentes con los pactos constitucionales y las leyes establecidas, se promueven también procesos de institucionalización que reducen los abismos entre estas dos esferas (la de los pactos reales- 
funcionantes y la de los pactos formales-institucionales), se inicia un proceso de reconocimiento; esto porque la norma no se pone por delante del sentido que opera en la vida cotidiana de la gente, aunque pueda ser o no su consecuencia.

5) Se menciona la posibilidad de que el encuentro real con la voluntad ajena potencie el paso del uso pragmático y ético de la razón práctica al uso moral. Ese encuentro resulta, de algún modo, de la posibilidad del cambio en el modo de plantearse los problemas desde la perspectiva ética hacia la perspectiva moral, desde un problema formulado de modo egocéntrico hacia un problema formulado en términos de bien común (ver Habermas, 2000: 124). Esto, personalmente, lo podemos interpretar como un modo en el que se pone en evidencia que el encuentro con el otro real y concreto puede ser detonador, puede ser la fuente, del uso moral de la razón práctica. De algún modo el uso ético y el uso moral, separados en el análisis, se vinculan en el proceso de motivación moral, es decir, en el proceso de generación de la acción moral.

Como lo podemos ver hasta aquí, algunas consideraciones que Habermas deja por fuera en el proceso argumentativo marcado en sus textos -los problemas de las fuentes de la moral- están contenidos como presupuestos o garantías implícitas en su discurso. Si bien entendemos que su intención es sólo sobre entenderlos y no desarrollarlos, quizás porque es un terreno precisamente ambiguo, hacerlos explícitos nos ayuda a definir políticas de acción más precisas para la motivación al diálogo en los casos que hemos descrito. 
Emmanuel Levinas:

la relación con el otro y la ética del encuentro

Levinas nos ayuda a pensar el problema de la negación al diálogo desde una propuesta muy clara: el Otro, que tiene en el vínculo su lugar fundamental. Para Levinas, la esencia de un verdadero diálogo está en la relación con el Otro. Pero depende de cómo se entienda esa relación.

De la Totalidad hacia el Otro como infinito

Hay una forma de pensamiento, y con ella una filosofía, que subsume bajo sus parámetros todo lo que se le presenta. Lo que conoce o puede conocer limita, por decirlo así, el tamaño del mundo, como si el conocimiento fuera el único vínculo posible con él, o más aún, como si todos los vínculos pudieran reflejarse en la unidad del conocimiento. Entonces, como personas que pensamos los problemas -como filósofos de profesión, por ejemplo-, corremos el riesgo de reducir el mundo y esos problemas a nuestra comprensión e interpretación, al modo como los pensamos. En eso consiste, para Levinas, el pensamiento de la Totalidad.

Así transcurren las relaciones con los otros, desde esa Totalidad: se subsume al otro bajo los cánones propios -lo que Levinas llama el Mismo- y sólo así se le reconoce. Es una forma de pensar el mundo cerrada a la diferencia, a la alteridad, y en este sentido, totalizadora y anuladora del Otro. Nos hace imaginar a quien va por ahí convencido de que no hay un «afuera» de las fronteras del conocimiento, de la razón.

Pero esto no es todo. Frente a la Totalidad se presenta el Infinito como aquello que la desestabiliza, la quiebra. El infinito es el Otro en su rostro. «El modo por el cual se presenta el Otro, 
que supera la idea del Otro en mí, lo llamamos, en efecto, rostro» (Levinas, 1977: 74); no como la manifestación de sus cualidades sino en su expresión, como aquel a quien nunca podré totalizar ni abarcar completamente, en cuanto siempre excederá mis formas de pensarlo, clasificarlo, categorizarlo. Por eso es infinito, porque se presenta como lo absolutamente inasible, impensable. De esta manera, la totalidad se rompe en el Infinito que es el Otro, no en la idea «adecuada» que me hago de él.

La relación con el Otro surge del Deseo de Infinito, un deseo metafísico. Consiste en el deseo desmesurado, de lo imposible, de lo que no puedo siquiera esperar (como la propia esperanza opera, por ejemplo, innumerables veces en nuestra experiencia) y por lo que tiendo, en concreto, al Otro. Porque es el rostro del Otro la cara del Infinito. Siendo un deseo que sucede en mí, nace fuera de mí, en el Otro. Y es un deseo que, frente a la presentación del «objeto» de deseo, no cesa, es permanente; sin embargo, la Totalidad siempre puede pretender abarcar al otro y anularlo, convirtiendo lo trascendente en inmanente, en parte de sí Mismo; como quien reduce el infinito a la idea que se hace de él y no admite un «más allá» de esa idea. La totalidad, en este sentido, es la sustantivación del infinito que, precisamente al sustantivarlo, los despoja de su infinitud.

Surge entonces la necesidad de la crítica. Ante el Otro concreto, el yo retrocede, pues se sabe incapaz de totalizarlo. Surge la conciencia de la arbitrariedad de la propia libertad y la necesidad de liberarla - paradójicamente- de tal arbitrariedad (ver Levinas, 1977: 109). El hombre levinasiano no es libre cuando se afirma en sí mismo, sino cuando se libera de su propia arbitrariedad, cuando se pone coto ante el Otro y asume su responsabilidad. La relación con el otro transcurre, de modo originario, en un ámbito de justicia que va en la dirección de la apertura al Otro. De allí no podemos escapar. 
Con Levinas, la crítica y la autocrítica a las propias formas y modos de pensar es fundamental, no por lo que pensamos, sino por las formas que estructuran nuestros modos de pensar las cosas y, especialmente, los otros.

Pero el lenguaje y la moral también ocupan un lugar en el pensamiento levinasiano. El cara a cara es el modo privilegiado de esa relación metafísica; el rostro del otro destruye la idea que de él podemos hacernos, acabando con las generalidades y neutralidades. Es en ese cuestionamiento, en esa interpelación del otro en mí en donde surge la palabra y surge la conciencia moral (ver Levinas, 1977: 120). No es la palabra el medio por el que surge la relación, sino al contrario, es en la relación con el otro donde se genera la palabra. El modo primario de la relación no es el lenguaje. Incluso la propia moral es posterior; es, como la palabra, secundaria respecto a una relación que transcurre más allá de ella. Levinas reconoce que hablar con alguien es hacer conciencia, y la conciencia es moral en cuanto surge del cuestionamiento de mi libertad y, ulteriormente, del Otro que se encuentra entre muchos otros; sin embargo, el vínculo es previo a la palabra.

El encuentro con el Otro como fuente del diálogo

Partiendo de la interpretación del planteamiento de Emmanuel Levinas como una ética fundada en el encuentro con el Otro, o siendo más fieles a su vocabulario, «ética de la proximidad», surge una serie de consideraciones que expongo a continuación, sobre el problema de las posibles fuentes del diálogo.

1) Es necesaria la autocrítica a las formas de pensamiento de la totalidad, como formas totalizadoras e incluso totalitarias, que restringen la relación y comprensión del 
mundo a vínculos de un solo tipo (racionales). Para dejar paso a otros vínculos, la crítica o ese sano escepticismo del que posteriormente nos habla el autor es fundamental. Incluso la moral, con un discurso positivo y muchas buenas intenciones, puede estar envuelta en esa Totalidad y constituir una farsa.

2) Es el Otro el que nos abre las puertas a otras formas de pensamiento, pues es su rostro el que nos hace ver que hay otros vínculos, no racionales, preoriginarios. Así como el infinito, siendo en su idea, me empuja a su reconocimiento, así el otro, siendo en su rostro, en la proximidad, me empuja a su reconocimiento. Es la ida hacia adelante ante lo imposible lo que media la relación, es la chispa que pone en relevancia otros vínculos. Es un reconocimiento en el que está implicada la ambigüedad de la relación. La crítica surge de la conciencia de la diferencia entre lo que conozco y la permanente tendencia a lo desconocido; entre la racionalización del mundo y lo que escapa a la razón, entre la totalidad y el infinito.

3) Con Levinas parece requerirse la presencia de elementos no racionales de vinculación con el Otro. Ante esta necesidad se perfilan dos opciones que ahora sólo mencionaremos y desarrollaremos posteriormente en las conclusiones: o la racionalidad se une a otros elementos no racionales que se constituirían en fuente de la acción moral, y caemos en el debate internalismoexternalismo; o ampliamos las fronteras de la propia racionalidad a estos elementos, lo cual equivaldría a admitir ambigüedades, desestabilizando los parámetros de la racionalidad.

4) Es posible el reconocimiento del otro sin una racionalidad común. Para Levinas, se puede ser sensible 
al rostro del Otro sin que medie primeramente la racionalidad en ello. Lo más importante, para dialogar, es abrirse al otro, ser sensible a su manifestación, mirarlo y escucharlo antes de lo que dice; mirarlo y escucharlo a él, luego sus palabras. La sensibilidad llega a ser punto de partida ineludible; el fortalecimiento de la mirada personal, humanizadora, y no teorética y totalizadora, parece fundamental. Esto es posible en cuanto hay un mundo de vínculos diversos con el Otro, que están a la base del reconocimiento. No todo se agota en la relación mediada por la razón.

Cuando analizamos los supuestos o condiciones que hacen posible el diálogo en la ética discursiva bajo las consideraciones que derivan del enfoque propuesto por Emmanuel Levinas, consideramos que se generan nuevas posibilidades de interpretación sobre el problema de la motivación moral para el diálogo.

Conclusiones generales: hacia el diálogo desde dos niveles

La motivación moral forma parte de los procesos de diálogo y deliberación que surgen como alternativa para la solución pacífica de los problemas sociales que afectan a muchas de nuestras sociedades. En este sentido, la resistencia habermasiana al incluirla como parte de su teoría puede llegar a ocultar una realidad humana y sociopolítica que parece ineludible, sobre todo en sociedades que se encuentran en proceso de consolidación democrática.

Mientras Habermas nos sitúa directamente en el nivel del lenguaje, necesario y fundamental para el desarrollo del diálogo, Levinas llama la atención sobre la necesaria inclusión 
de otro nivel: el de los vínculos. Bajo esta doble perspectiva, no abrimos espacio únicamente al desarrollo de un diálogo para el que ya están ganadas las voluntades, sino que contemplamos la posibilidad de que tales voluntades, desde el mismo momento en que se vinculan de diversos modos, empiezan a generar puentes que, ulteriormente, pueden derivar en el establecimiento del tan ansiado diálogo.

El mismo enfoque pragmático del lenguaje que asume Jürgen Habermas es la primera puerta que, desde ámbitos como la psicolingüística, la sociolingüística o la propia teoría de la argumentación, se abre para reconocer la importancia de las fuentes no lingüísticas y en cierto sentido no racionales de nuestras acciones discursivas. Se trata, asumiendo el vocabulario de nuestros autores de referencia, del nivel lógico-pragmático habermasiano, necesitado del nivel metafísico levinasiano; de un orden discursivo radicado en una eticidad fundamental y precedente; sin embargo, debemos tener cuidado cuando nos referimos a ese nivel metafísico. No se trata de un nivel metafísico dogmático, sino al contrario, metafísico crítico, donde la eticidad levinasiana se plantea como condición de posibilidad abierta a la pluralidad de contenido, a todo otro. En este sentido, el vínculo con el Otro es, para Levinas, la plataforma sobre la cual ha de situarse todo hecho comunicativo, lo cual tiene obvias pero retadoras consecuencias para una pedagogía orientada al diálogo.

A continuación, algunas ideas de cierre para la reflexión.

1) Reconstruyendo el pensamiento de Habermas desde su concepción de la razón práctica recordamos la importancia de sus fuentes kantianas, donde el uso moral implica la concepción de la persona como ser libre. En este sentido, la ética habermasiana parte de la liber- 
tad como uno de sus fundamentos y, desde allí, como la otra cara de la moneda, se eleva el reconocimiento del otro como ser igualmente libre: me reconozco digno, luego puedo reconocer la dignidad del otro. El gran aporte habermasiano a esta tradicional interpretación de la herencia ética kantiana es que tal libertad no implica una racionalidad monológica sino, al contrario, se trata de una racionalidad que se reconoce tal en la dialogicidad que le es propia: soy digno/le hablo, el otro es digno/lo escucho. Por lo tanto, no hay forma de constituirse racionalmente sino en el diálogo con los otros.

Si bien Levinas reconoce la libertad en el hombre, la moral no surge de ella sino, de modo indirecto, de la vergüenza -un sentimiento- que ella como libertad arbitraria produce frente al Otro.

Para Levinas, la libertad centrada en la individualidad y la interioridad del ser comienza siendo arbitraria, y es frente al otro, como exterioridad, donde se transforma en conciencia moral. La moral se funda en el cuestionamiento que se produce frente al rostro del Otro.

2) Tanto Habermas como Levinas reconocen, uno desde la libertad individual y otro desde la responsabilidad por el otro, la presencia de la relación en la fundación de la moral. La diferencia está en que, para Habermas, la relación acontece en el lenguaje, mientras para Levinas es anterior, incluso a la razón, la palabra y a la propia moral -de allí que podamos entenderla como su fundamento-. Para Habermas el vínculo se constituye con el otro cuando decido dar razones frente a él 
y lo escucho; para Levinas, estoy afectado-vinculado con el otro cuando me encuentro frente a él, ya desde el modo humano de estar en el mundo, y desde allí surge la palabra y la moralidad.

La palabra, para Levinas, es como un segundo momento del encuentro frente al otro. En el cara a cara se revela el Otro y en la palabra la relación adquiere sentido y significación dentro del mundo del conocimiento. Lo racional descansa en lo ético en cuanto radica en ese recibimiento del rostro, en el lenguaje que surge en el encuentro.

3) Para Habermas, la moral la encontramos al nivel del lenguaje, como construcción argumentativa propia de la racionalidad comunicativa. Para Levinas, si bien la ética está a un nivel previo, metafísico, la moral se presenta igualmente como desarrollo ulterior $\mathrm{y}$, en ello, el lenguaje se hace presente; de hecho, el lenguaje es expresión positiva de esa relación metafísica; sin embargo, a pesar de esta semejanza que no esperábamos encontrar entre los autores, es importante aclarar que una cosa es que la moral se presente como farsa, como discurso totalizador y articulado sobre deberes y derechos de pretensión universalista pero desprovisto de su fuente universal originaria, y otra es que, remitiéndose a sus orígenes, busque construirse y consolidarse desde la relación cara a cara con el Otro, dentro de un proceso crítico de apertura y aceptación permanente de la diferencia. Recordemos que para Levinas la moral es cuestionamiento, «recibir al otro es cuestionar mi libertad».

4) En ambos autores la presencia del otro afecta positivamente a la persona, en una dirección favorable a la 
motivación para la acción moral. El Otro, para Levinas, como cuestionamiento a la arbitrariedad de la propia libertad; en el pensamiento habermasiano, como voluntad ajena real que genera un cambio de problemas, no referidos únicamente al propio ego, sino a situaciones relativas al bien común.

5) Para ambos autores somos morales porque tenemos una estructura ética que nos empuja a ello. La eticidad habermasiana se funda en la estructura racional comunicativa, mientras la eticidad levinasiana lo hace en la estructura de la proximidad, del encuentro cara a cara; así, y en consecuencia, mientras la eticidad habermasiana es de origen individual, la eticidad levinasiana es de origen relacional, lo cual nos permite identificarla como una ética del encuentro o la proximidad.

6) Consideramos que los autores se pueden trabajar de modo complementario: si bien Habermas se instala en una racionalidad comunicativa y desde allí ve el panorama, no deja de ser cierto que para el propio Levinas esa racionalidad comunicativa es uno de los momentos de desarrollo de la relación con el Otro. Lo que aporta Levinas, bajo nuestra perspectiva, es el sentido crítico de lo no contemplado; en otras palabras, permite cuestionarnos acerca de lo no previsto, lo descartado, lo no incluido -irónicamente- dentro de la teoría incluyente de Jürgen Habermas.

Hay países, y sobre todo personas, que no logran hacerse con las herramientas comunicativas necesarias para participar del actuar comunicativo que los incluye y que, a pesar de ello, no merecen ser excluidos. Un modo de excluirlos es pretender que se sabe cuál es su voz; lo que resulta de ello es más ex- 
clusión. Esto porque no se les mira, quizás, en su diferencia; aquí Levinas resulta fundamental. Su aporte nos empuja a reconocer la experiencia de los vínculos que nos pueden llevar a mirar y escuchar a los otros con algo más que las razones aceptadas como tales. Finalmente, se trata entonces de procurar una ética y una moral construida desde varias dimensiones de lo humano, y no exclusivamente desde la racionalidad, el lenguaje, las emociones o los afectos. Se trata de ir maniobrando con la participación mayor o menor de estos aspectos, en la crítica y la construcción de teorías morales que puedan responder a situaciones problemáticas diversas, que son al fin y al cabo el motivo fundamental de la ética: hacer más humana la vida y la convivencia de todos.

El problema de la motivación moral parece ser uno de los problemas que más fácilmente pone en jaque el campo de acción de la filosofía moral. La pregunta por aquello que nos impulsa a ser morales o a optar por la moralidad nos pone al filo de campos como la filosofía, la psicología, e incluso la religión. Ello sin contar con disciplinas que apenas me atrevo a nombrar en el presente trabajo, como la neuroética, que también nos abre fronteras, entre otros campos de estudio. Con ello queremos decir que, si bien se pueden asumir respuestas inclinadas a una $u$ otra perspectiva, no resulta sencillo evadir las consideraciones que al respecto de los mismos asuntos se hacen desde otros puntos de vista.

Dentro de la propia teoría habermasiana, que pretende delimitar muy bien el ámbito de la teoría moral, es posible hallar el germen de la necesidad de ampliar la razón comunicativa a otras dimensiones no necesariamente lógico-pragmáticas y, de esta manera, salirse del carácter estrictamente cognitivo de su planteamiento. Surge la necesidad de incluir otros aspectos de la persona; o una razón unida a los sen- 
timientos, emociones y afectos, o una razón sentimental o compasiva que los vincule de modo intrínseco.

No estamos seguros de la postura que estamos dispuestos a asumir. La asunción de una posición al respecto parece requerir algo más de investigación en los procesos de motivación moral; sin embargo, si intentáramos calibrar la balanza para hacer juicio de las posibilidades que tenemos, vemos claramente dos de ellas, ya mencionadas cuando me refería a los aportes de Emmanuel Levinas, pero desarrolladas a continuación.

a) La consideración de la motivación moral a partir de una razón comunicativa ampliada: Una razón comunicativa que, sin dejar de ser racional, se alimente de diversos elementos que en principio se entienden como no racionales -emociones, afectos, sentimientos-. Se trata de una racionalidad comunicativa que no se restringe a la cognición sino que la abre a otros elementos. Se aproxima a la respuesta que, ante los límites de la racionalidad comunicativa habermasiana, han elaborado autores como Adela Cortina, donde el concepto de una razón cordial expresa la necesidad de ampliar las fronteras de esa razón comunicativa, reconociendo en ella una parte cordial o compasiva que es el asiento de la condición de la posibilidad del diálogo; es, en otras palabras, la fuente de la motivación moral para el diálogo. La razón comunicativa tiene en estos elementos una especie de condición protomoral que, estando dentro de los márgenes de la racionalidad no representa, aún, la expresión de la moralidad como tal. La motivación moral, igualmente radicada en esos elementos no cognitivos; sin embargo, queda incluida 
o integrada a la racionalidad, en una versión más amplia de la misma.

b) La consideración de la motivación moral a partir de vínculos diversos -no sólo racionales- con los otros: se traduce en el reconocimiento de diversas formas de establecer los vínculos con el Otro, donde no es la razón la mediación necesaria, sino, de otro modo, se refiere a un encuentro prelingüísto y precomunicativo donde aparece el otro y desde donde surge la palabra y el lenguaje; es éste el momento levinasiano del cara a cara, de la relación metafísica, de la relación ética en su sentido más fundamental. Desde esta perspectiva, la sintonía con el otro, el querer dialogar y, en resumen, la motivación al diálogo, no se generan en elementos racionales sino en elementos afectivos, emocionales, sentimentales, previos. Desde esta segunda postura, pretender la racionalización de estos elementos podría ser incluso opacar su carácter, apagar la llama que los mantiene encendidos. Habría que ser críticos ante ello.

Cuando se trata, ya no de pensar en el desarrollo de una persona sino en el de una sociedad, creo que la primera postura, la de una razón comunicativa ampliada, termina por tener más sentido: ampliar nuestra concepción de la razón y, dentro de ella, incluir elementos que se mantenían fuera de sus márgenes. Eso sí, siempre atentos a las formas de pensamiento en las que estamos, no vaya a ser que, sin darnos cuenta, estemos negando la posibilidad de que otras formas encuentren aceptación en nosotros. No podemos instalarnos sin más en nuestros modos de ver, sentir y pensar el mundo.

Indudablemente los discursos morales, vengan de donde vengan, hacen sus aportes en la consolidación de valores y 
modos de vivir cada vez más humanos; de ello no tenemos duda; sin embargo, hay elementos previos a los discursos en los que hay que trabajar. A ello me refiero con todo lo que se desprende del trabajo de Levinas con relación a los modos de juzgar y promover las relaciones entre las personas, con enormes consecuencias para la pedagogía de la moral.

Si sólo hablamos y construimos desde los discursos del bien, apoyados en la propia validez del lenguaje, creyendo que tienen sentido por sí mismos, estamos ignorando el vacío que genera la farsa que emerge en situaciones marcadas por las contradicciones de la guerra -declarada o no-, la marginalización, la falta de voluntad y disposición a la paz. Es importante tejer la moral desde las relaciones del cara a cara, como encuentro fundante en el proceso de conquista de formas más humanas de vivir y convivir.

\section{Bibliografía}

Bohman, J. (1996). Public deliberation. Pluralism, complexity and democracy. EEUU: MIT Press.

Cortina, A. (2011). Neuroética y neuropolítica. Sugerencias para la educación moral. Madrid: Tecnos.

Cortina, A. (2007). Ética de la razón cordial. Asturias: Nobel.

Cortina, A. (2004). Democracia deliberativa. Rubio, J., Salmerón, M. y Toscano, M. (eds.). Ética, ciudadanía y democracia. Contrastes. Revista Internacional de Filosofía, Colección Monografías.

García Marzá, D. (1992). Ética de la Justicia. J. Habermas y la ética discursiva. Madrid: Tecnos.

Gonzalez Fabré, R. (2008). Desafíos socioculturales de la vida pública en Venezuela. En Virtuoso, Francisco (coord.). 
Una mirada sobre Venezuela. Reflexiones para construir una visión compartida. Caracas: Centro Gumilla.

Habermas, J. (2008). La inclusión del Otro. Barcelona: Paidós.

Habermas, J. (2000). Aclaraciones a la ética del discurso. Madrid: Trotta.

Habermas, J. (1998). Facticidad y validez. Madrid: Trotta.

Levinas, E. (2003). De otro modo que ser o más allá de la esencia. Salamanca: Sígueme.

Levinas, E. (1977). Totalidad e infinito. Ensayo sobre la exterioridad. Salamanca: Sígueme.

Levinas, E. (2006). Ética como Filosofía Primera. En A parte Rei. Revista de Filosofía, 43, en http:/ / serbal.pntic.mec. es / cmunoz11/ lorca43.pdf, consultado en junio 2012.

Merkel, W. (2004). Embedded and defective democracies. Democratization, 5(11), pp. 33-58.

Moreno, A. (2008). El aro y la trama. Miami: Convivium Press. 
Resumen

A continuación presento las conclusiones de una investigación motivada por la necesidad de crear condiciones para el diálogo en sociedades no consolidadas democráticamente. Planteo una relectura de la ética discursiva habermasiana desde las críticas que hace Emmanuel Levinas a la filosofía de la Totalidad y, desde allí, propongo una serie de aportes, incluso complementarios, entre los autores. El diálogo se hace posible, pero implica la consideración de otros niveles de análisis que en principio no están contemplados en la teoría de Jürgen Habermas.

Palabras clave: ética, razón comunicativa, democracia deliberativa, totalidad, infinito, otredad.

\section{Abstract}

These are the conclusions of an investigation prompted by the need to create conditions for the dialogue in societies with defective democracies. I suggest a reading of Habermas's discourse ethics from the criticisms of Emmanuel Levinas's Philosophy of Totality and from there, i propose a series of contributions, even complementary, among the authors. The dialogue is possible, but involves considerations of other levels of analysis that are not addressed, in principle, in the theory of Jürgen Habermas.

Keywords: ethics, communicative rationality, deliberative democracy, totality, infinity, otherness. 